\title{
Data Analysis: Plankton Distribution in Internal Waves in Massachusetts Bay
}

\author{
Jesús Pineda \\ MS 34 Biology Department \\ Woods Hole Oceanographic Institution \\ Woods Hole, MA 02543 \\ phone: (508) 289-2274 fax: (508) 457-2134 email: jpineda@whoi.edu \\ Scott Gallager \\ MS 35 Biology Department \\ Woods Hole Oceanographic Institution \\ Woods Hole, MA 02543 \\ phone: (508) 289-2783 fax: (508) 457-2134 email: sgallager@whoi.edu \\ Alberto Scotti \\ Dept. of Marine Sciences, Venable Hall, CB \# 3300 \\ University of North Carolina, Chapel Hill, 27599-3300 \\ phone: (919) 962-9454 fax: (919) 962-1254 email: ascotti@unc.edu \\ Award Number: N00014 -01-1-0172 \\ http://science.whoi.edu/labs/pinedalab/
}

\section{LONG-TERM GOALS}

Our long-term goals are describing and understanding the mechanisms responsible for plankton accumulation and transport in large amplitude internal waves.

\section{OBJECTIVES}

The general objective of our research is to observe the effect of tidally generated undular bores on near-surface plankton distribution. The particular objectives are (1) to determine the spatial scales of plankton distribution compared to the physical features before, during and after the internal tidal bores, and (2) to resolve whether plankton is concentrated by the physical characteristics of the bores. If there is a pattern in the plankton distribution associated to the bore, then another objective is (3) to determine whether plankton accumulation is dependent on plankton behavior, and to resolve whether taxa redistribute differentially in specific regions of the bore.

\section{APPROACH}

We are using an observational and theoretical approach (Pineda et al. 2002). Our observational program includes following internal bores as they propagate from Stellwagen bank to Scituate, in Massachusetts Bay. The bores are sampled with a shipboard Doppler current meter (velocity and backscatter), a $200 \mathrm{KHz}$ backscatter transducer, and a towed video plankton recorder (VPR), which captures images, and records depth, conductivity, temperature, fluorescence, light attenuation and 


\section{Report Documentation Page}

Form Approved

OMB No. 0704-0188

Public reporting burden for the collection of information is estimated to average 1 hour per response, including the time for reviewing instructions, searching existing data sources, gathering and maintaining the data needed, and completing and reviewing the collection of information. Send comments regarding this burden estimate or any other aspect of this collection of information,

including suggestions for reducing this burden, to Washington Headquarters Services, Directorate for Information Operations and Reports, 1215 Jefferson Davis Highway, Suite 1204, Arlington

VA 22202-4302. Respondents should be aware that notwithstanding any other provision of law, no person shall be subject to a penalty for failing to comply with a collection of information if it

does not display a currently valid OMB control number.

1. REPORT DATE

30 SEP 2003

4. TITLE AND SUBTITLE

Data Analysis: Plankton Distribution in Internal Waves in Massachusetts

Bay

6. AUTHOR(S)

7. PERFORMING ORGANIZATION NAME(S) AND ADDRESS(ES)

MS 34 Biology Department,,Woods Hole Oceanographic

Institution,,Woods Hole,,MA,02543

9. SPONSORING/MONITORING AGENCY NAME(S) AND ADDRESS(ES)
3. DATES COVERED

00-00-2003 to 00-00-2003

5a. CONTRACT NUMBER

5b. GRANT NUMBER

5c. PROGRAM ELEMENT NUMBER

5d. PROJECT NUMBER

5e. TASK NUMBER

5f. WORK UNIT NUMBER

8. PERFORMING ORGANIZATION

REPORT NUMBER

10. SPONSOR/MONITOR'S ACRONYM(S)

11. SPONSOR/MONITOR'S REPORT

NUMBER(S)

12. DISTRIBUTION/AVAILABILITY STATEMENT

Approved for public release; distribution unlimited

13. SUPPLEMENTARY NOTES

14. ABSTRACT

15. SUBJECT TERMS

16. SECURITY CLASSIFICATION OF: a. REPORT

unclassified b. ABSTRACT

unclassified c. THIS PAGE

unclassified
17. LIMITATION OF ABSTRACT

Same as

Report (SAR)
18. NUMBER 19a. NAME OF

OF PAGES

7 


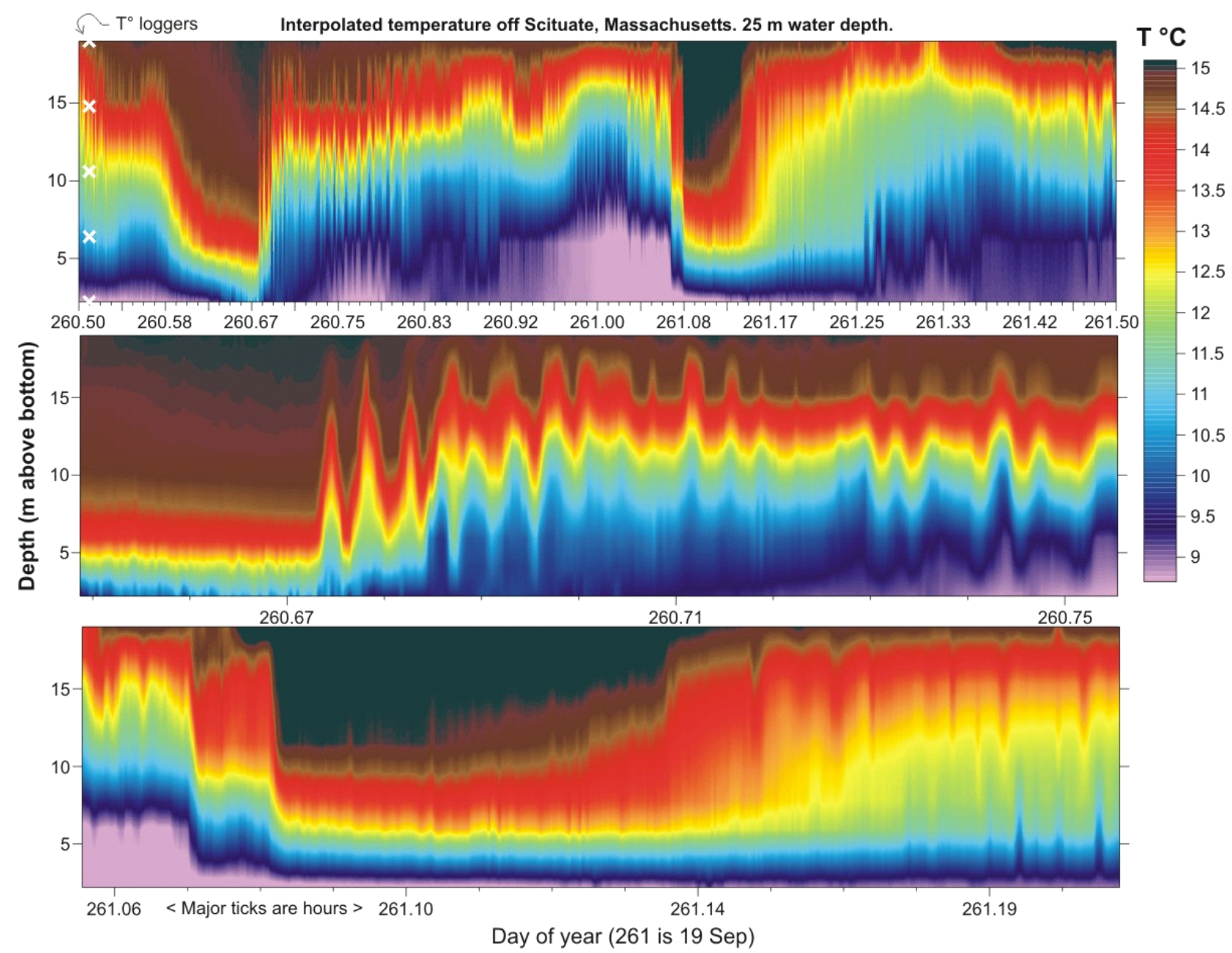

Figure 1. Time series of interpolated temperature at 25 water depth. The middle and bottom panels are amplifications of the bottom top panel. White crosses on the top panel indicate temperature logger position

[The top panel shows that the whole water column oscillated from warm to cold in about 12.h hours.

The middle panel shows that when the temperature is cooling, higher-frequency (few minutes) internal waves of elevation lead the cooling. However, when the water column is warming periodic internal waves are missing.]

Photosynthetically Active Radiation. In addition bores are observed with moored instruments, including a moored video plankton observatory system ("AVPPO"), temperature moorings, and Doppler current meter profilers. Our observations on particle accumulation by the bores will be contrasted with an internal bore model (Scotti and Beardsley, ms. a \& b). The bore model will also be used to guide our observational program. In general, Pineda and Gallager are responsible for the observational portion of the program, while Scotti is in charge of the theoretical aspect. 


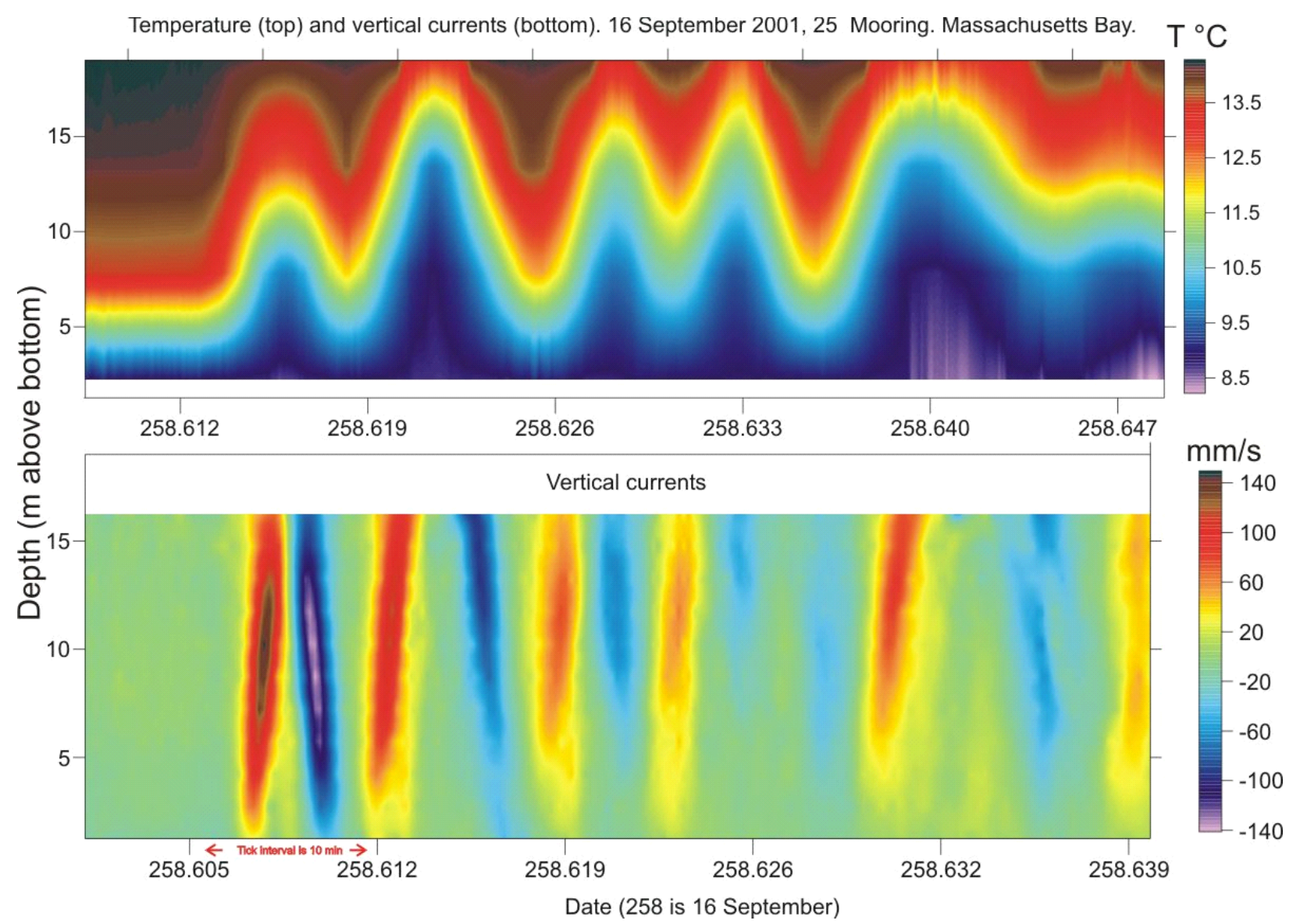

Figure 2. Time series (about 1 h) of interpolated temperature (top) and vertical currents (bottom) at 25 water depth. Temperature and $1200 \mathrm{kHz}$ Doppler currentmeter moorings are separated a few 10 's $\mathrm{m}$. Sampling interval is $8 \mathrm{~s}$ for the temperature, $16 \mathrm{~s}$ and bin size is $0.75 \mathrm{~m}$ for the current meter. Panels are displaced to match temperature and circulation patterns.

[The top panel shows a train of internal waves with periods of about 10 minutes and wave heights of up to $10 \mathrm{~m}$. The bottom panel shows a pattern of upward and downward currents corresponding to the waves, with maximum upward and downward currents of $14 \mathrm{~cm} / \mathrm{s}$.

\section{WORK COMPLETED}

The fieldwork component consists of two cruises, one in 2001 and another in 2002. Both cruises used the R/V Connecticut. Work in the 2001 cruise was described in our previous report. In 2002 our cruise dates were from 30 September to 11 October. We deployed three temperature moorings, located at 25, 30 and $45 \mathrm{~m}$ water depth, and one Doppler current profiler at $45 \mathrm{~m}$. The instruments acquired high frequency time series of temperature and water currents. We also obtained hourly profiles from seabed to surface of plankton, temperature, conductivity, fluorescence, light attenuation at 5 frequencies (AC-9), and up and down-welling irradiance with the AVPPO. We sampled several internal bore fronts as they propagated westward from Stellwagen bank, both during daytime and nighttime. Sampling was completed with the VPR (plankton, temperature, conductivity and depth) and with a shipboard $600 \mathrm{kHz}$ Doppler current meter (backscatter, velocity), and a Biosonics $200 \mathrm{KHz}$ system. We were unable to locate the internal wave packets at the beginning of the cruise, possibly because the high frequency motions dissipated before detection. By 3 October, however, we observed 
the first packet of many during the cruise. Because of gear malfunctioning, we returned to Woods Hole for one day, after which we sampled several more packets of internal bores. The data set is very rich, and the analysis of the physical data is well advanced.

To analyze the data, we have developed a new method to process raw ADCP data that, in addition to accounting for the spatial extension of the waves, provides an estimate of the direction and speed of propagation (Scotti et al., a ms.). The 2-Dimensional model of the internal tide in the bay is now completed, and was used to estimate the baroclinic energy flux (Scotti et al, b, ms.).

\section{RESULTS}

A preliminary analysis of the data recorded in the shallow water location $(\sim 25 \mathrm{~m})$ shows an internal wave field characterized by the semidiurnal passage of a broad wave of depression (Fig. 1). High frequency waves of elevation are usually found on the trailing edge of the depression (Fig 1, starting

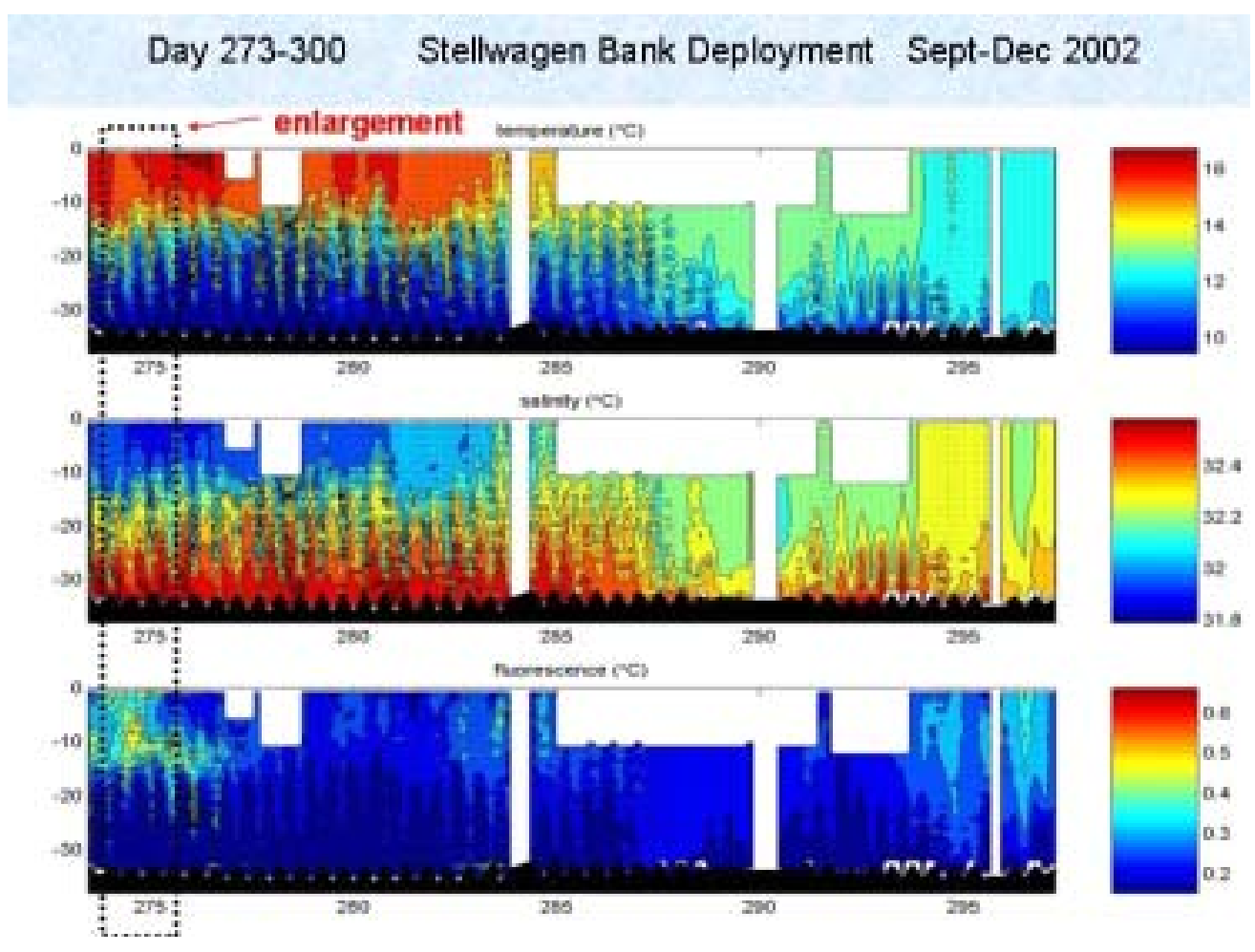

Figure 3. Time series of interpolated temperature, salinity and fluorescence obtained with the AVPPO (about 45 m water depth).

[The three panels show that the variability is dominated by oscillations with a period of about $12 \mathrm{~h}$. After day 287, the layered patterns are much less conspicuous, indicating a reduction in the water column stratification.]

high frequency waves are found on the leading edge of the depression. From the timing and phase of these structures, and from the results of our numerical model, we infer that the broad waves of depression observed at the two sites and the undular bores observed in Stellwagen Basin (e.g. Haury et 
al. 1979, Chereskin 1983) are different expressions of the same disturbance that originates every tidal cycle over Stellwagen Bank and moves shoreward with an estimated phase speed ranging from 40 to over $70 \mathrm{~cm} / \mathrm{s}$. In deep water $(\sim 70 \mathrm{~m})$, our shipboard observations show that the disturbance has the form of an undular bore of depression. As it moves into shallower waters, the bore looses its undular character, a feature that is predicted by our model and can be ascribed to the strongly nonlinear interaction with the shoaling bottom. During this process, part of the baroclinic energy originally contained in the undular bore is lost to dissipation, but a significant fraction (about $60 \%$ ) is transmitted onshore. There, the disturbance appears as a strongly nonlinear internal tide, which lowers and raises the thermocline over a period of a few hours. Often, the lowering of the thermocline is gradual. The restoring process, the cooling of the water column, is usually accompanied by the presence of high-frequency nonlinear waves of elevation, that can be occasionally very steep (see Figs. 1 and 2) and associated with large vertical velocities of up to $14 \mathrm{~cm} / \mathrm{s}$ (Fig. 2). Using the method described above, we infer that the train of waves shown in figure 2 propagates to the $\mathrm{WNW}$ at $23 \mathrm{~cm} / \mathrm{s}$. Because the amplitude of the displacement is about $10 \mathrm{~m}$ (both integration of the vertical velocity and analysis of the temperature data support this estimate), the slope of the waves is $\mathrm{O}(1)$, which is far above the range of validity of current weakly nonlinear theories. To the best of our knowledge, this is the first time such extreme undular bores are observed in the ocean. The alternate presence of cold and warm bodies of water in the nearshore (Fig. 1) represents energetic cross-shore and vertical exchange of parcels of water at very short time scales, as described qualitatively by Pineda (1994). Thus, sharp semidiurnal variability occurs at both depth stations, but our preliminary observations suggest that the high-frequency waves of depression associated with the phase where the thermocline is deepening occurs mostly at the $45 \mathrm{~m}$ depth station. In contrast, waves of elevation predominate at $25 \mathrm{~m}$ and are associated with the leading edge of the shallowing of the thermocline.

Presence of such an energetic internal wave field, coupled with its relatively predictable nature, has important effects on the spatial and temporal distribution of zooplankton. A month long time series of data from the AVPPO shows the semidiurnal internal tide followed by disruption of stratification following passage of a storm (Figure 3). Figure 4 shows an expanded two day section of these data and select profiles of total zooplankton, dominated by krill and calanoid copepods.

The combination of towed VPR data and $200 \mathrm{KHz}$ acoustic backscatter from the Biosonics unit revealed a strong association of plankton with temperature in the internal wave front, but on occasions the correspondence between plankton and acoustic backscatter was poor. This underscores the importance of measuring particle and plankton distributions independently of acoustics before acoustic backscatter can be interpreted correctly. 


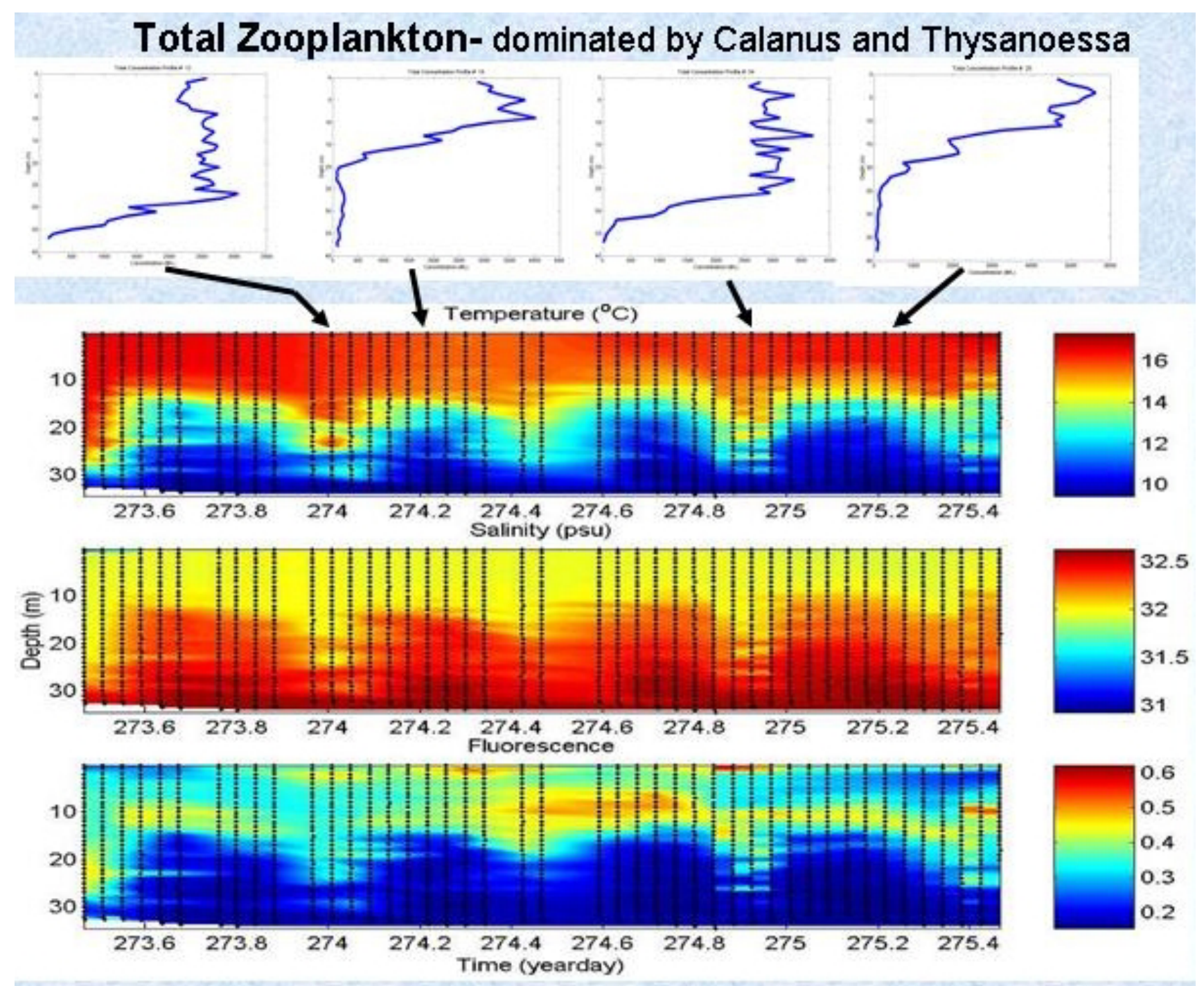

Figure 4. Zooplankton depth profiles, and time series of interpolated temperature, salinity and fluorescence obtained with the AVPPO (about 45 m water depth).

[The three bottom panels show that the variability is dominated by oscillations with a period of about $12 \mathrm{~h}$. The three upper profiles show the vertical distribution of copepods and krill being compressed and expanded as the thermocline shallows and deepens.]

\section{IMPACT/IMPLICATIONS}

Our research will shed light on the formation and persistence of zooplankton patchiness by internal bores and waves, and whether zooplankton behavior influences this pattern. We will also contribute to the interpretation of acoustic backscatter information in relation to physical and biological properties of internal waves. 


\section{RELATED PROJECTS}

Scotti is currently funded by the ONR to develop a comprehensive 3-dimensional model to study the interaction on nonlinear waves with topography. The data collected in shallow water will be used to validate the model.

\section{REFERENCES}

Chereskin, T. K. 1983. Generation of internal waves in Massachusetts Bay. Journal of Geophysical Research:2649-2661.

Haury, L. R., M. B. Briscoe, and M. H. Orr. 1979. Tidally generated internal wave packets in Massachusetts Bay. Nature (Lond.) 278:312-317.

Pineda, J. 1994. Internal tidal bores in the nearshore: warm-water fronts, seaward gravity currents and the onshore transport of neustonic larvae. Journal of Marine Research 52:427-458.

Pineda, J., S. M. Gallager, and A. Scotti. 2002. Tidally generated undular bores and near-surface plankton distribution in Massachusetts Bay: a combined observational and theoretical approach. EOS, Trans. AGU Ocean Sciences Meet. Suppl. 83:296.

Scotti A. and R. Beardsley. a. Large internal waves in Massachusetts Bay. Part 2: Modeling generation, propagation. To be submitted to JGR.

Scotti A. and R. Beardsley, b. Large internal waves in Massachusetts Bay. Part 3: Modeling shoaling. To be submitted to JGR.

Scotti A, R. Beardsley, B. Butman and S. Alexander. a. A modified beam-to-earth transformation to measure large-amplitude high-frequency internal waves with an ADCP. To be submitted to JTECHO.

Scotti A., R. Beardsley, B. Butman and S. Andersen, b. Large amplitude internal waves in Massachusetts Bay. Part 1: Observations. To be submitted to JGR. 